\title{
Escribir el poema de la democracia. En memoria de Richard Rorty (1931-2007) ${ }^{1}$
}

\author{
To Write the Poem of Democracy. \\ In Memory of Richard Rorty (1931-2007)
}

\author{
Martha Palacio Avendaño ${ }^{2}$ \\ Universitat Oberta de Catalunya
}

A la hora de trazar una semblanza de la obra del filósofo estadounidense Richard Rorty (1931-2007) le asalta a una la duda de qué rasgo debería privilegiar y así ofrecer a los lectores las pistas adecuadas con las que valorar su aporte filosófico. Si conviene separar las hebras entre su contribución a la filosofía del lenguaje, a la filosofía política o mejor destacar ese tono desenfadado con el que buscó alterar el ritmo de la conversación filosófica en el interior de la academia.

Cualquiera que sea el rasgo o hebra elegido, no cabe duda de que el trabajo de Rorty imprimió un aire diferente al debate de las ideas filosóficas; le aportó frescura al sugerir el abandono de preguntas habituales, especialmente aquellas orientadas a la fundamentación de nuestras prácticas, $\mathrm{y}$ al definir nuevos cauces a este quehacer. Nos propuso dirigir nuestros esfuerzos a evaluar qué utilidad podría tener el sostener determinadas creencias y si estas podrían ayudarnos a cambiar el modo de hacernos cargo de la realidad.

Si interpretamos su trabajo como el resultado de aplicar esta premisa pragmatista de evaluar la utilidad de las creencias que sostenemos, entonces las diferentes hebras que tejen su filosofía nos devuelven una trama consistente en la que las consecuencias de su filosofía del lenguaje tienen implicaciones sobre las formas de entender la discusión política y, sobre todo, su idea de democracia y de ciudadanía liberal.

Esta trama es la que da cuenta del cambio propuesto por Rorty a la filosofía de abandonar la tarea de fundamentación de las prácticas y, en cambio, ofrecer algunas opciones para la creación compartida del sentido sobre lo que puede resultarnos útil como sociedad.

Su visión pragmatista de la filosofía orientada a la utilidad social de las creencias y las prácticas es, sin embargo, pragmática y se diferencia de modo sustancial de otros enfoques pragmatistas como el de H. Putnam (1926-2016) o el de R. Bernstein (1932), con respecto al estatuto de la experiencia y la preeminencia del lenguaje como herramienta de acción social.

\footnotetext{
1 Algunos apartes de este escrito han sido tomados de mi tesis doctoral y modificados ligeramente cuando ha sido necesario. Palacio A., M. Implicaciones éticas y políticas de la "creación de si" a partir de la fillosofía de Richard Rorty, Universitat de Barcelona, 2014.

2 Profesora de Teorías de la justicia de la facultad de Estudios de Derecho y Ciencia Política.
} 
Rorty fue hijo de su tiempo y su filosofía, por tanto, está moldeada por las circunstancias históricas de la mitad del siglo XX. Nos referimos a la guerra fría, los posteriores esfuerzos de superación ante el fracaso del discurso emancipatorio y el ulterior triunfo del capitalismo aupado sobre el discurso ideológico de la democracia liberal. Esto se traduce en un rasgo compartido por el pensamiento posmoderno caracterizado por la desesperanza que, sin embargo, en su caso particular se desplaza hacia un lenguaje posibilista centrado en la firme convicción de que la libertad es el primer dato del que partimos. La libertad del individuo es el punto de arranque de lo que queramos hacer con nosotros mismos, dirá Rorty; y, en consecuencia, no necesita fundamento ninguno ni requiere ser puesta en cuestión.

Este lenguaje posibilista unido a la libertad como dato incuestionable representa un punto de inflexión de la filosofía al final del siglo XX que tiene consecuencias sobre el rol del intelectual en lo que para él fuera el conjunto de las sociedades prósperas de Occidente. A ellas va dirigido su discurso sobre lo que pensó debían ser los derroteros de una nueva filosofía y con esta el de un nuevo pragmatismo filosófico; a saber, cambiar la forma en que hablamos de determinadas cosas y con ello dar curso a la ampliación de la experiencia de la libertad.

El primer libro de Rorty El giro lingüístico (1967) es una compilación de los trabajos más relevantes en la filosofía del lenguaje practicada en los Estados Unidos. Rorty preparó la edición y una introducción en la que da cuenta tanto de los cambios de acento y modulaciones de esa filosofía como de su importancia en la historia del pensamiento. La obra acabó por convertirse en una obra de referencia, a la que diez años más tarde su autor volvió a revisar para su re-edición añadiendo una aclaración importante en la que nos explica ya no las promesas de esta filosofía, sino sus limitaciones, y denuncia el enroque de un trabajo filosófico que aspira a un metalenguaje que evite los malentendidos del filosofar. Rorty lamentaba la pretensión cientificista de esa filosofía en la que se pierde el tono de un trabajo al que posteriormente él denominará como conversacional. Pues para él, y de acuerdo con la tradición pragmatista, la filosofía habría de entenderse como una larga e inacabada conversación que nos permita acercarnos a la creación de términos nuevos, a decir cosas que no hayan sido escuchadas con anterioridad, a desplazar la forma en que relacionamos las cosas entre sí o nos enfrentamos a ellas. ${ }^{3}$

Ese fue el propósito de Rorty en La filosofía y el espejo de la naturaleza (1979), donde, siguiendo a Dewey, rastrea las huellas de la idea del ser humano como una entidad destinada a conocer y de la filosofía como encargada de aportar el fundamento a esa experiencia cognoscitiva y a las prácticas a que da lugar. El objetivo de Rorty era mostrar de qué modo se producen los cambios de léxico o de paradigma, cómo se producen las revoluciones conceptuales que nos dotan de imágenes sobre lo que hacemos y somos capaces de realizar. Rorty se confronta en este libro con la premisa básica de la modernidad que afirma que el hombre puede, en virtud de su conocimiento, dominar a la naturaleza y, en consecuencia, sistematizar las formas de experiencia de la vida humana. La crítica de esa pretensión cognoscitiva será la que conduzca a nuestro autor a sugerir que hay otro modo de acercamiento a la

3 Palacio A., M. 2014, p.15. 
realidad: la experiencia de la conversación, y a proponer la filosofía como una labor hermenéutica, una indagación que se da en y por el lenguaje. ${ }^{4}$

El lenguaje es para Rorty una práctica social que se justifica a través de su ejercicio. De ahí que, el objetivo tradicional de la filosofía de aportar un fundamento resulte inadecuado para una práctica que se ve sometida a la temporalidad. La revisión crítica del paradigma epistemológico en la tradición filosófica que Rorty lleva a cabo en La filosofía y el espejo de la naturaleza es el resultado de su esfuerzo por dinamitar la pretensión cientificista de la filosofía, de superar el legado de la filosofía del lenguaje analítica y circunscribir a la filosofía en el terreno de las prácticas sociales entroncando así con el rechazo pragmatista al cartesianismo. ${ }^{5}$

Esta intención de Rorty marcará toda su reflexión posterior y hará que se presente como un nuevo pragmatista, como alguien cuyo trabajo puede volver a situar al pragmatismo como un contendiente importante del debate filosófico a finales del siglo XX. ${ }^{6}$

En Consecuencias del pragmatismo (1982) Rorty planteó de modo más claro su desplazamiento desde la filosofía analítica hacia el pragmatismo, y nos presentó a este último como suficientemente dotado para construir una nueva etapa en el quehacer filosófico, al que denominará post-filosofía. Con posterioridad, su trabajo recogido en cuatro volúmenes de ensayos filosóficos publicados entre 1991 y 2007 -año de su muerte-, ${ }^{7}$ matizarán cuidadosamente que la labor de la filosofía consiste en proponer nuevos lenguajes que nos empujen más allá de los hábitos y que den lugar a prácticas sociales distintas. Esos lenguajes nos despojarán de las certezas para instalarnos en el terreno de la contingencia y la esperanza social. Dicho de otro modo, Rorty propone que abandonemos la Verdad y nos quedemos con la intersubjetividad, dando paso a la práctica de la solidaridad en términos epistémicos y prácticos. ${ }^{8}$

Esta sería la clave de lectura para comprender la propuesta de la "creación de si" que aparece en Contingencia, ironia y solidaridad (1989). Fue este un libro asaltado por innumerables detractores, que se percataron de las dificultades de una labor filosófica que renunciaba a los valores más sagrados: la búsqueda de la verdad y la pretensión de una fundamentación del yo, del lenguaje y de la comunidad. Los efectos de esa devastación rompían los cauces de la fundamentación teórica de la política, de la ética, y ofrecían como respuesta una apuesta por el relato moral como puerta de entrada a una nueva manera de pensar los problemas sociales y políticos de nuestro tiempo. La práctica conversacional adecuada al trabajo filosófico, según Rorty, desplazaría el acento de nuestra capacidad de conocer y presentaría como forma de acercamiento a la realidad nuestra capacidad inventiva, la imaginación que, a través

\footnotetext{
${ }^{4}$ Palacio A., M. 2014, p.16.

${ }^{5}$ Ibidem.

${ }^{6}$ Ibidem.

7 Se trata de Objetividad, relativismo y verdad. Ensayos filosóficos 1, 1991 (v. cast. 1996); Heidegger y otros pensadores contemporáneos. Ensayos filosóficos 2, 1991 (v. cast. 1993); Verdad y progreso. Ensayos filosóficos 3, 1998 (v. cast. 2000); y, Filosofía como politica cultural. Ensayos filosóficos 4, 2007 (v. cast. 2010).

8 Palacio A., M. 2014, p.17.
} 
de la ironía como crítica, permite lo que denomina como la creación de sí y del nosotros. ${ }^{9}$

En estas condiciones el trabajo filosófico para Rorty consiste en una política cultural, en un trabajo de modificación de las relaciones que establecemos con las cosas, que se centra alrededor de las preguntas sobre "quiénes somos", cuál es nuestra comunidad de referencia con arreglo a las prácticas que realizamos y qué esperanza social nos cabe albergar para cumplir con el proyecto de la solidaridad. ${ }^{10}$

Este esfuerzo por ampliar el registro de lo posible a través de la imaginación es una tarea poética que aspira a mostrar de qué forma ella es el mejor resorte contra las trampas del prejuicio -que suele cultivar la crueldad, el miedo liberal por excelencia-- ${ }^{11}$ El relato nuevo, la forma de hablar diferente abre paso a la profecía en el sentido de aquello que aún no ha sido escuchado, lo que ahora puede decirse y, en consecuencia, ser de otro modo. Rorty introduce así la idea de que la posibilidad de hacer mutar nuestro conjunto de creencias, cambiar de léxico, es una labor que debe mucho no solo a la noción del conductismo epistemológico, sino también a la simpatía de $\mathrm{D}$. Hume, porque esta emoción moral nos pondría en la senda de plantearnos con W. James “¿cuál es la diferencia que hace la diferencia?”. En otras palabras, lo que da origen al desplazamiento de unas creencias por otras pasa siempre por el tenue gesto que consiste en preguntarse ¿qué pasaría si...? La simpatía humeana abre entonces el camino al experimentalismo científico y moral en que consiste imaginarnos siendo otros/as.

El experimentalismo es otra forma de hablar de la redescripción, de proponer relaciones diferentes, nuevos juegos del lenguaje en los que ya el tejido de creencias y deseos se modifica. La imaginación como expresión de la libertad es la herramienta adecuada para que tanto el yo como el nosotros reclamen moldear su identidad, inaugurar una nueva forma de vida.

Esta es la labor social que cumple el poeta en la conversación de Rorty: proponer otros lenguajes que sugieran que la relación con la verdad se construye como efecto del anhelo humano por expandir la libertad.

Se trata de un programa de reforma social de la democracia liberal bajo el cual se anida un desplazamiento tanto ontológico como político por parte de Rorty al sugerir que moldear la realidad es el efecto de la redescripción, de un nuevo tejido de haces de relaciones en los que el lenguaje ya no dice lo que es, pues no puede representar la realidad, sino que es la herramienta para crear lo que convenimos en llamar realidad.

Este discurso posibilista de la libertad articulado por la imaginación, el emotivismo moral y la ductilidad de las creencias como hábitos de acción, sostiene frente al racionalismo de las teorías de la justicia, que no hay mejor pegamento social que la solidaridad: el anhelo de un proyecto por construir una nueva identidad política.

\footnotetext{
${ }^{9}$ Ibid.

${ }^{10}$ Ibid.

${ }^{11}$ Rorty, R. Contingency, Irony, and Solidarity, Nueva York, Cambridge University Press, 1989, cit. Shklar, J. Ordinary Vices. Cambridge, Massachusetts: Harvard University Press, 1984.
} 
La solidaridad, diríamos, es la proyección de la "imaginación sentimental" que habría de poner en movimiento a la empatía. Es la intencionalidad de vernos como otros distintos a lo que somos, de experimentar con otras formas de vida alentados por la crítica y la ironía, aunque sin llegar a poner en peligro el marco político de la democracia liberal sin el cual estas ya no serían actitudes esperables de un ethos democrático. Como apuntara J. Habermas en su obituario de Rorty:

«Él sabía que una democracia solo mantiene su carácter robusto y "atlético" por medio del criticismo». ${ }^{12}$

La ironía poética o el pensarse de otro modo no es, entonces, una reinvención en toda regla, sino que puede llegar a ser un gesto desesperado de quien sabe que no puede deshacerse de su pasado. Por ello, cuando Rorty habla de la creación de sí del poeta a través de un nuevo léxico no está sugiriendo una creación ex-nibilo, sino señalando el pathos de quien aspira a poder decir de su pasado, como Nietzsche, "así lo quise". El nuevo léxico que aspira a inaugurar un tiempo nuevo ha de asumir, sin embargo, el temor de su caducidad, de una nueva redescripción que lo desplace. Hacerle frente a esta contingencia impone una forma de vida en la que nadie pueda suponer el ajuste perfecto de su léxico, sino someterlo a la construcción compartida de los términos que sirvan a la elaboración de un proyecto como el de la solidaridad. El poeta no es entonces alguien que lidia con su léxico personal; por el contrario, el poeta al que Rorty se refiere es el reformador social porque el poema que hay que escribir es el de la democracia liberal.

El objeto de Forjar nuestro país (1998) fue precisamente señalar de qué forma el poema de la democracia podría reescribirse por parte de la izquierda estadounidense. De qué manera, la deslocalización empresarial difícilmente se combatiría ocupándose de la deconstrucción textual y sí, en cambio, proponiendo alternativas de cohesión que ayudaran a elaborar la culpa de la guerra del Vietnam, relatos que superaran el egoísmo y el sadismo en vez de continuar la batalla cultural por el canon entre departamentos de humanidades. El objetivo debía ser articular un discurso que resultara de interés a las preocupaciones de los ciudadanos, proponer un nuevo vocabulario moral que estimulara a crear alternativas progresistas, las necesarias para hacer frente a la globalización de un capital apátrida y al descenso de las condiciones de vida de los estadounidenses.

Rorty era consciente de que la democracia que él conocía corría peligro, que se trataba de un constructo frágil, primero, en tiempos de la guerra fría para los que veían en el comunismo un enemigo; y, más adelante en el tiempo, volvía a ser frágil ante la pérdida de una utopía, pues sin relato emancipatorio ¿qué hacer con la libertad?, ¿dónde situar la esperanza ante la deriva de un escenario tan triunfante como vacío?; en épocas más recientes como la nuestra, la de la globalización del

12 Habermas, J. «...And to Define America, Her Athletic Democracy». El filósofo y formador del lenguaje. Ideas $y$ V alores, 138, 2008, pp. 5-17. 
capital, ¿cómo cuidar de la democracia? Si «[...] la democracia liberal funciona en tiempos de prosperidad económica, y no en tiempos de inseguridad económica [...]» ${ }^{13}$.

Es cierto que la creación de sí fue su respuesta, la maleabilidad del yo, esa contingencia en la que, además, se dan cita las otras dos: la de la comunidad y la del lenguaje.

Esta respuesta filosófica se vio acompañada de otra serie de intervenciones por su parte en las que, ofrecer un relato diferente para forjar su país consistiera en: primero, una apuesta decidida por introducir en la academia un lenguaje más ligero a la vez que desenfadado - un giro retórico que no debería distraernos ante la profundidad de sus tesis y que apuntalaba la deficiencia argumentativa del oponente ante el choque con sus propias creencias-. Segundo, un esfuerzo por hacer de su propia filosofía una conversación entre la filosofía analítica, el pragmatismo y la filosofía continental. Tercero, ayudar a tejer puentes entre los dos lados del Atlántico; Rorty junto a R. Bernstein y J. Habermas atendieron y alentaron encuentros sobre filosofía y ciencia social durante el período de la guerra fría, en la ciudad de Dubrovnic, con intelectuales del otro lado del telón de acero. Encuentros que acabaron por sentar las bases de lo que hoy conocemos como el Congreso Internacional de Teoría Crítica. ${ }^{14}$ Esta misma actitud conversacional que propicia el experimentalismo quizá permita explicar, también, el por qué Rorty, una vez logró posicionarse en la filosofía académica, decidió renunciar a la estrechez de los departamentos de filosofía y optó por elaborar su reflexión en el contexto del departamento de literatura comparada -un ambiente al parecer más propicio para tender puentes entre tradiciones de pensamiento y sensible a la elaboración de lo que entendiera por filosofía edificante y al cultivo de la más amplia ironía-. La filosofía entendida entonces como una práctica conversacional sería, a su juicio, la forma más natural de asumir que la racionalidad es una práctica social y que, por tanto, todo esfuerzo de animar la conversación no solo favorecería a la filosofía sino a un ethos democrático que alentaría aquellas actividades que lo fortalecieran. La consolidación de su obra junto a la inconformidad con la forma de entender la filosofía le habrían permitido con el paso del tiempo alcanzar el título de ser un intelectual público en la sociedad estadounidense. Así, ante el fenómeno de masas que en los Estados Unidos representan los académicos de prestigio y que podría desvirtuar la idea de un intelectual público en dicha sociedad, conviene recordar que Rorty se mantuvo próximo a sus conciudadanos al ofrecerles, en formatos alejados del paper académico, ${ }^{15}$ argumentos por la defensa de la democracia liberal y de mantener viva la opción de la experimentación: ampliar el lenguaje moral con que cuenta una sociedad para pensarse a sí misma. Esta fue la forma de contribuir a forjar su país.

\footnotetext{
13 Rorty, R. Cuidar la libertad, ed. Eduardo Mendieta. Trad. Sonia Arribas, Madrid, Trotta, 2005, p.166.

${ }^{14}$ Los coloquios que comenzaron cerca del año 1977 se han mantenido ininterrumpidamente durante las últimas décadas y ahora tienen como denominación la de International Conference on Critical Theory. Véase Bernstein, Richard J. Beyond Objectivism and Relativism: Science, Hermeneutics, and Praxis. Filadelfia: University of Pennsylvania Press, 1983, esp. p. xii; Brabec, Martin The Twentieth International Conference on Critical Theory in Prague. International Critical Thought 2, 4, 2012, 511-515; y, Palacio, A., M., 2014 donde me ocupo de situar estos encuentros respecto a la relación entre pragmatismo y teoría crítica.

${ }_{15}$ Algunos de esos artículos previamente publicados en el New York Times, New Times Magazine, Dissent y London Review of Books están recogidos en Rorty, R. Philosophy and Social Hope, Nueva York, Penguin Books, 1999.
} 
Rorty, sin hacer uso de un tono grave ni agorero y consciente de que era un autor de fin de siglo, habría querido llamar la atención de los filósofos para que al experimentar con formas novedosas de pensar los problemas también se hicieran cargo de atender a la democracia ya que, si de esta no cuidaban, la creatividad y la libertad se verían pronto amenazadas y la posibilidad de disfrutar de una conversación filosófica podría perderse.

Esta fragilidad de la democracia es la que, creemos, le llevó a decir en 1997:

«Mi lema es que, si cuidamos la libertad, la verdad se cuidará a sí misma. Un enunciado verdadero es aquel sobre el que una comunidad libre está de acuerdo en que es verdadero. Si cuidamos la libertad, obtenemos de regalo la verdad.»» ${ }^{16}$

Palabras que suenan desenfadadas como corresponde al antifundacionalismo de su posfilosofía, y que hoy, en cambio, ante las consecuencias más cuestionables de las soberanías compartidas, el actual déficit de la democracia y la dilución de la libertad política nos recuerdan la necesidad de defender una vida en democracia; esto es, tener el valor de poner a prueba nuestros mejores argumentos en la discusión pública como en la conversación filosófica. Quizá sea este uno de los mejores legados rortianos que, además, invita a iluminar las sombras de su idea de democracia.

Este dossier ha sido preparado a la luz de la idea de filosofía como conversación atendiendo tanto al pathos del diálogo socrático como a la apuesta de Ch. S. Pierce de "la comunidad de investigadores". Dos imágenes que hacen posible evocar las palabras de W. James de que la "huella de la serpiente humana se halla en todas las cosas", esto es, que difícilmente podamos contar con ideas que no tengan su asiento y sentido en la experiencia humana, en la interacción y, por tanto, en el "conflicto de narrativas", ${ }^{17}$ y en la capacidad de transformar aquello que nos importa.

Hemos invitado a colaboradores expertos, profesores de filosofía política y moral que se han dedicado pensar con Rorty y desde Rorty las condiciones de la vida contemporánea. A título personal les agradezco que hubieran aceptado la invitación y que se sintieran concernidos a nutrir con sus reflexiones lo que aquí pretende ser una conversación sobre el legado de Rorty. De la misma manera que nuestro filósofo abogó por la idea de ampliar la democracia a través de la reforma social, pensar su propio tiempo, nuestros estudiosos han optado por señalar las ausencias en el pensamiento de Rorty y elaborar una perspectiva que con la distancia de diez años de su desaparición refleja la pertinencia de su pensamiento a la hora de señalar las consecuencias del giro posmoderno como efecto de un cambio sustantivo en las relaciones humanas y en la forma de hacernos cargo de nuestra realidad.

\footnotetext{
16 Rorty, R. Op. Cit, p. 165.

${ }^{17}$ Bernstein, R. American Pragmatism: The Conflict of Narratives, en Saatkamp, Herman J. Jr. (ed), Rorty and Pragmatism. The Philosopher Responds to His Critics. Nashville: Vanderbilt University Press, 1995, pp. 54-68.
} 
El profesor Gabriel Bello, catedrático emérito de Filosofía moral de la Universidad de La Laguna, nos conduce a través de su texto "Richard Rorty: la filosofía como política cultural, deconstrucción del autoritarismo y ética contingente" a valorar la idea rortiana de "la prioridad de la democracia sobre la filosofía". Para ello, G. Bello se centra, sin embargo, en aquella otra idea de "la filosofía como práctica cultural" que explicita aún más que la tarea filosófica consiste en moldear las creencias que nos constituyen y aportar el léxico que aumente el sentido de un ethos democrático. Esto sería posible, dice Bello, recuperando a Derrida como compañero de viaje de Rorty; es decir, deconstruyendo los esquemas autoritarios que anidan en la visión dicotómica de las categorías a través de las que pensamos y que legitiman las asimetrías de poder. El Rorty que nos presenta G. Bello es un Rorty que, a su juicio, hace gala de un "humanismo prudente", aquel que, basado en una ética contingente, le devuelve al yo el sentido de ser la medida de todas las cosas.

Desde otra perspectiva, el profesor José Manuel Bermudo, catedrático emérito de Filosofía política de la U. Barcelona, también se hará cargo de la cuestión de que el yo sea entendido como medida de todas las cosas. En su texto "La seductora levedad del ser", Bermudo reconstruye las condiciones en que se elabora el discurso de la subjetividad y de qué modo se produce la subjetivación de lo real en la filosofía contemporánea. Se trata, nos dirá, de allanar el terreno en el que se instalará la topografía de la contingencia. Esta reconstrucción histórico filosófica encuentra en Rorty a uno de sus mejores exponentes y a su idea de la 'creación de sí' como la acertada expresión de que la realidad contemporánea se ha desplazado de "la insoportable levedad del ser", de la que hablara M. Kundera, a una levedad seductora. Este diagnóstico de nuestro tiempo elaborado al hilo de la historia de la filosofía es a la vez una contribución alineada con el esfuerzo de Rorty por ampliar el canon filosófico y hacer dialogar a la literatura con la filosofía. Bermudo propone así una reconstrucción de la filosofía política contemporánea a la luz de la narración de la levedad del ser.

Por su parte, el profesor Norbert Bilbeny, catedrático de Filosofía moral de la Universidad de Barcelona, en su texto "Richard Rorty y el papel de la imaginación en el progreso humano" presenta una lectura cuidadosa de una de las más recientes publicaciones póstumas de R. Rorty Philosophy as Poetry (2016). Bilbeny da cuenta de la importancia del experimentalismo de Rorty en materia moral; la idea de que la capacidad inventiva de los seres humanos aporta a la racionalidad práctica los cauces por los que transitará. Así, la poesía y el romanticismo acompañan a la razón y a la argumentación en el esfuerzo de dar cuenta de las prácticas humanas y su modificación. En este caso, hacer de la filosofía algo similar a la poesía supone asumir la tensión entre el anhelo por conjurar la finitud de la vida humana y la aceptación de esa contingencia.

El rol de la imaginación en el progreso humano configura en el pensamiento de Rorty una clave de lectura para definir a los movimientos sociales que han ampliado el léxico moral de la deliberación política. En este caso, el artículo "Feminismo, emancipación y pragmatismo", de mi autoría, presenta el intercambio argumental entre Rorty y Nancy Fraser a propósito del feminismo en los Estados Unidos en el decenio de los noventa. Los dos pensadores debaten si el pragmatismo sería una herramienta útil para el proyecto emancipatorio de la igualdad de las mujeres. Destaco, sin embargo, de qué manera el historicismo de Rorty y su com- 
prensión de los movimientos sociales como grupos articulados alrededor de preferencias subjetivas, constituyen un obstáculo a la comprensión del sentido emancipatorio de la lucha feminista, por una parte; y, de otra, reducen el carácter crítico asignado a la imaginación en la transformación política.

A modo de cierre del dossier presentamos la última entrevista concedida por Rorty antes de su fallecimiento y realizada por los profesores de la Universidad de Querétaro José Salvador Arellano y Robert T. Hall. Agradecemos a la Universidad de Querétaro el que nos haya concedido el permiso de su reedición. La entrevista realizada el 18 de enero de 2006 con motivo de una visita de Rorty a México, repasa cuestiones claves del pensamiento de nuestro autor como el problema del realismo y el historicismo; la educación sentimental y la promoción de la democracia liberal; la relación entre romanticismo y pragmatismo; y, termina con la discusión sobre la izquierda cultural en los Estados Unidos.

Finalmente, acompaña a esta edición del monográfico dedicado a la obra de Rorty dos reseñas que podrían vincularse a la indagación rortiana. Una de ellas la de Lluís Pla Vargas sobre las dificultades del discurso liberal de la ciudadanía de que trata el libro del Jaime Fierro titulado "La ciudadanía y sus limites," y la del Rafael Valera Nogueira sobre el libro de Ignacio Castro Rey, Ética del desorden. Pánico y sentido en el curso del siglo que presenta la idea del enfrentamiento a la contingencia de la vida humana.

Como una invitación final a mantener la conversación filosófica, creemos que hay que revisar a Rorty con la perspectiva que da el tiempo; navegar en su lectura pertrechado de herramientas alternativas que prueben los límites de sus tesis y que puedan elaborar una aproximación serena sobre lo que fue su preocupación constante: la fragilidad del poema de la democracia.

Antes lo mencionábamos, para Rorty los reformadores sociales escriben el poema de la democracia, aquellos que convienen en la necesidad de la filosofía y de otras prácticas que promuevan la crítica, la ironía y el experimentalismo, pues todas ellas son formas de ejercitar la libertad y ampliar la conversación.

A nuestro juicio, Rorty entendió el proyecto colectivo del poema de la democracia como un hacer uso de la herramienta del pragmatismo con el fin de que la filosofía como conversación también sirviera a la reforma social y presentará argumentos que estimularan la ampliación de la experiencia.

A diez años de su muerte, un balance de su legado filosófico sugiere algo más que abrazar algunas de sus tesis, y en cambio sí, tomarle la palabra de que el pragmatismo como experimentalismo sería una buena herramienta para ampliar los cauces de nuestra experiencia, para modificar las condiciones que para él debían quedar inalterables porque para nosotros la libertad sí es un dato cuestionable y, por tanto, difícil de ejercer para muchas y para tantos más ya no solo en las democracias prósperas de occidente como efecto de la actual globalización del capital, sino para quienes nacen viven y crecen en los espacios diseñados para el sostenimiento de la libertad de la que Rorty, en cambio, sí pudo gozar. 